\title{
F wie ... oder nehmen Sie doch den Zug
}

\section{Dominik Heim}

PD Dr. med., Klinik Hohmad, Thun, Mitglied FMH

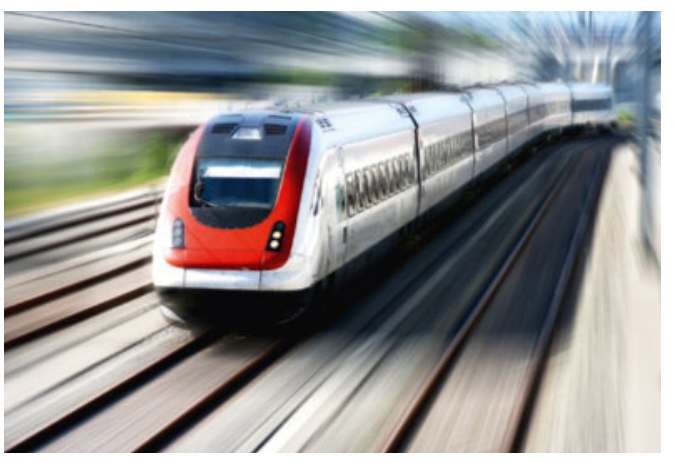

Ich habe das Privileg, häufig an Kongresse gehen zu dürfen.

Man bucht einen billigen Ein-Handgepäck-Flug, und schon ist man am Ziel. Man trägt dabei zwar etwas zu den 20000 Flugbewegungen am Tag in Europa bei, aber das gilt im Klima der America-first-Ära leider als nebensächlich.

Aber - die Zahnpasta gehört ins Plastiksäckli, weil flüssig. Der kleine Rucksack mit dem PC ist keine Aktentasche und passt nicht in die Messbehälter beim Einchecken in Amsterdam, auch der ausladende Invicta-Rucksack, das Ein-Handgepäck, passt nicht. Die Säge des Sackmessers ist etwas länger als $6 \mathrm{~cm}$, deshalb kürzt man sie netterweise in Genf mit dem «Elephanten", dieser Zange, die wir sonst für die Schanzschen Schrauben beim fixateur externe brauchen. In Sofia gelten dann aber auch diese $6 \mathrm{~cm}$ nicht, und die Frage ist

\section{Der Zug! In der Schweiz sind wir verwöhnt. Fast immer ist er pünktlich.}

einfach, das Sackmesser zu behalten, in Sofia zu übernachten und am nächsten Tag auf anderes Sicherheitspersonal zu hoffen, oder ohne Sackmesser in Athen um Mitternacht doch noch anzukommen. Die Kette am Sackmesser darf ich ohne Sackmesser behalten. In Kiew ist der Bus am Gate zu klein, also drückt man, und jeder zieht den Bauch ein, bis sich die Türen dann doch noch schliessen. In der Ukrainian Airlines hofft man vergebens auf einen Drink, ausser man zahlt ihn in Euro - aber das kennt man ja auch von andern Billigfluggesellschaften. Im Flugzeug drin kämpft man dann um einen Platz im Gepäckabteil, das Kind schreit mordio, und die Eltern können es nicht beruhigen - ein frühes ADHS?

Der Zug! In der Schweiz sind wir verwöhnt. Fast immer ist er pünktlich. Und wenn er frühmorgens knapp nach 6 Uhr doch einmal zu spät aus dem LötschbergLoch herauskommt, was die Walliser in Bundesbern (und den Bundesrat, der in Kandersteg wohnt) verspätet ankommen lässt, kommt man mit dem luxuriösen ICE über Olten doch noch nach Luzern (meine Arbeit bei der Suva). Denn trotz gleichem Namens- beginn warten Lötschberg und Luzern den Anschluss nicht ab. Man muss aber beim Einchecken am Billetschalter (so man kein GA hat) nicht verschämt seine eben zu grosse Aktentasche auf den Boden stellen, auf dass man nur den Rucksack am Rücken sehe (eben den blauen Invicta). Das Wägeli kommt im «Oberdeck dieses Wagens» (Zugansage) (noch). Man steht nicht im nervigen Stau, wobei das - man denke an den Gotthard an Ostern - viele Leute nicht zu nerven scheint. Man ist dann vielleicht etwas weniger «à jour mit den News», weil man nicht den privaten MainstreamRadiosender gehört hat, aber dafür entschädigt dann die 20-Minuten-Ausgabe am Morgen oder der unsägliche Blick am Abend, und so sind wir dann doch wieder im Bild über die Alltagstrivialitäten. Leider hat man viele Nachtzüge in Europa aus dem Fahrplan gestrichen, so dass man jetzt tagsüber mit dem TGV (bald inOui), mit der Frecciarossa oder mit dem Thalys durch die Landschaft rast. Die europäischen Städte rücken zusammen, Paris ist nicht mehr viel weiter als Genf-St.Gallen. Mit dem ICE ist man schneller in Frankfurt als mit dem einstündigen Flug. Man kann im Sessel versinken, entspannen oder arbeiten und in die neue CD Infinite von Deep Purple oder Is This the Life We Really Want von Roger Waters hineinhören. Denn dank Trump, dem Leader With No Fucking Brain, geniessen wir nochmals (das letzte Mal?) das musikalische Kaleidoskop des Ex-Pink-Floyd-Mitglieds. Und wir blättern im aktuellen Krimi aus Press \& Books und gratulieren uns zum Kauf des Portugal-Krimis Lost in Fuseta von Gil Ribeiro, A Real Must!

An den ESTES-Kongress in Valencia werde ich also trotz höherem Preis (und längerer Reise) mit dem Zug gehen und dabei einen Chardonnay trinken, wie das früher in den englischen Bestsellern zum guten Ton gehörte. Nach Melbourne fährt leider kein Zug, ich werde meine Zahnpasta im Plastiksäckli verstauen und bei der Gepäckabmessung das Modewort mit F, das Country Joe and the Fish am längst verblichenen Woodstock Festival vor 50 Jahren in die singende Menge gepeitscht haben, aus meinem Flugvokabular streichen. Yeah!

Bildnachweis

(C) Shuttlecock | Dreamstime.com 